\title{
Quando o coletivo alcança a fotografia
}

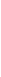

Eduardo Queiroga

Artigo recebido em: 25/04/2016

Artigo aprovado em: 21/04/2017 


\title{
Quando o coletivo alcança a fotografia
}

\author{
When photography becomes collective
}

\author{
Eduardo Queiroga*
}

Resumo: $O$ artigo se propõe a diferenciar as práticas dos "coletivos fotográficos contemporâneos" - que surgem com maior intensidade no início do século XXI - em relação a outras experiências que agruparam fotógrafos ao longo da história, em especial os fotoclubes, as agências e o projeto de documentação Farm Security Administration. Observa também a atuação dos fotógrafos Endre Friedman, Gerda Taro, Hilla e Bernard Becher.

Palavras-chave: Fotografia. Coletivo fotográfico contemporâneo. Agência fotográfica. Fotoclube.

Abstract: The paper aims to distinguish the practices of "contemporary photo collectives" - that come with greater intensity at the beginning of the XXI century - in relation to other experiences that grouped photographers over the history, especially the photo clubs, agencies and the project Farm Security Administration. It also remarks the work of the photographers Endre Friedman, Gerda Taro, Hilla and Bernard Becher.

Keywords: Photography. Contemporary photo collective. Photo agency. Photo club.

* Doutor em Comunicação pelo Programa de Pós-Graduação em Comunicação da Universidade Federal de Pernambuco (PPGCOM-UFPE). 
Dois argumentos muito comumente defendidos atrapalham a ideia de uma fotografia coletiva: de um lado o discurso automático; de outro, a individualidade. Qualquer iniciativa coletiva já parte, mesmo que inconscientemente, de um confronto a tais pensamentos. Ao longo da história, podemos listar uma série de experiências agrupando fotógrafos. Isso, no entanto, não significa, necessariamente, promover uma fotografia coletiva. Em meio ao surgimento de tantos coletivos fotográficos e não poucas argumentações de que os coletivos sempre existiram sob a forma de outros modelos, pretendemos resgatar o modo de operação e principais características dessas experiências, para defendermos que novas propostas são postas a partir dos coletivos fotográficos contemporâneos. Essas novas práticas colocam questões importantes para a fotografia e surgem com maior intensidade em princípios do século XXI.

O fenômeno é confirmado por um grande número de publicações e eventos dedicados aos novos coletivos (QUEIROGA, 2015). Para citar alguns encontros exclusivamente tributados ao assunto no Brasil e no mundo: Encontro de Coletivos Fotográficos Ibero-Americanos (São Paulo, 2008), Encuentro de Colectivos Fotográficos Euroamericanos (Madrid e Soria, Espanha, 2010), E.CO/14 (Santos, 2014). Além desses, muitos encontros de fotografia dedicaram edições especiais aos coletivos.

Uma primeira barreira a ser ultrapassada, que pode parecer resolvida em alguns círculos, mas que ainda se mostra muito presente em outros, é o entendimento de que a fotografia é fruto de um processo mecânico, maquínico. Antes de se pensar na inclusão de vários sujeitos, é preciso admitir, naturalizar a subjetividade na fotografia. Os motivos de tal barreira não são poucos e foram defendidos por pensamentos de diversas áreas, incluindo, com muita força, inventores, fotógrafos e apoiadores da nova atividade. Se esse discurso estava presente no anúncio do registro do daguerreótipo pelo governo francês, em 1939, ou se refletia no livro Pencil of Nature, de Talbot - outro importante personagem na 
trama fotográfica -, essa mensagem ainda circula no entendimento comum, na publicidade das grandes marcas ou mesmo em pesquisas teóricas recentes. Ou seja, uma barreira que queremos tomar como ultrapassada, mas que ainda reverbera na memória fotográfica de modo que não podemos deixar, pelo menos, de citá-la em uma discussão como a nossa. Anne McCauley, ao abordar métodos de investigação para a história da fotografia - ou histórias, no plural, como ela prefere - destaca uma dificuldade:

[...] a quase invisibilidade do fotógrafo como indivíduo criativo definido por suas obras também emerge em um estudo cronológico da monografia fotográfica. [...] Essa ausência reflete a nula importância que se outorgava aos fotógrafos individuais em uma sociedade onde a maior parte do trabalho fotográfico foi publicado anonimamente e na qual quase todos os fotógrafos foram tratados como artesãos e comerciantes (MCCAULEY, 2002, p. 307, tradução livre).

Passada essa dificuldade, é possível pensarmos uma fotografia coletiva? Esquecendo a ideia de uma imagem automática, espelho da realidade, transparente, sem código, que é formada unicamente pela sua ligação física com o referente, nos deparamos com uma outra imagem tão presente e defendida como a primeira. Passamos de uma ausência do sujeito para a individualidade. "Tirar fotos é uma técnica ilimitada de apropriar-se do mundo objetivo e também uma expressão inevitavelmente solipsista do eu singular" (SONTAG, 2004, p. 138). O fotógrafo é aquele indivíduo solitário, possuidor de um olhar diferenciado, carregado com várias câmeras, lentes, tripés, flashes - mais uma vez o equipamento. Não é assim que ele se apresenta no imaginário popular, tantas vezes explorado ou reforçado pela literatura, pelo cinema e pela televisão? A fotografia, não por coincidência, compartilha com a modernidade a conformação de um novo sujeito observador "isolado, fechado e autônomo em seu confinamento escuro, retirado do mundo" (CRARY, 1990). 
A câmera, por sua vez, é desenhada para ser operada por uma só pessoa. As novas tecnologias de operação remota dos equipamentos vêm permitindo mudanças nessa configuração do aparelho, mas esse "detalhe de desenho industrial" de um equipamento denuncia a demanda de um mercado individualista. Outro exemplo está em contratos e leis que enxergam o autor como um indivíduo. É possível a coautoria, mas como uma soma de indivíduos, não como um coletivo. Enfim, não vamos aprofundar essa ideia de individualidade, mas não podemos deixar de notar que se coloca como uma segunda barreira a ser transposta pela vontade de uma fotografia coletiva. A fotografia, pois, carrega consigo esses dois entraves ao entendimento coletivo. Muitas das experiências que reuniram fotógrafos reproduziram tais limites nos seus modos de operação.

Um primeiro modelo que agrupa aficionados por fotografia é o dos fotoclubes. Surge em meados do século XIX, e reúne pessoas com as mais variadas ligações com a linguagem: profissionais, amadores e técnicos. Uma característica importante: são sociedades fechadas, clubes, cujos associados tentam se diferenciar do usuário comum da fotografia, galgam um nível mais elevado de conhecimento da técnica e uma maior experimentação da linguagem. O início desses grupos é marcado pela busca por um reconhecimento como arte e uma distinção do fotógrafo "caseiro", aquele que agora pode comprar uma Kodak e registrar suas viagens, o aniversário ou o casamento na família. "O movimento fotoclubista surgiu como uma reação amadorista à massificação da produção fotográfica predominante" (COSTA; SILVA, 2004, p. 22). O fotoclubismo teve forte ligação com o pictorialismo e atuou em cidades do mundo inteiro. No Brasil, importantes representantes da fotografia moderna surgiram no interior de fotoclubes. $O$ experimentalismo - não somente com o pictorialismo mas também a partir de outras influências internacionais que passaram até pelo surrealismo - foi uma característica importante nesses grupos, resultando em novas pesquisas técnicas e estéticas. 
A troca de informações entre os participantes foi um ponto chave para o desenvolvimento de tais experimentações e inovações, mas sua característica - genética - de distinção garantia um traço de competitividade interna muito marcante. Foram muitos os concursos, salões e outras formas de disputa, chegando, até, a duelos fotográficos - onde um integrante desafiava um rival para tirarem a limpo qual dos dois era melhor fotógrafo (COSTA; SILVA, 2004, p. 24). Várias eram as maneiras de distinção interna: “a vida do fotógrafo no interior dos fotoclubes era marcada pela competição. Havia uma hierarquia que classificava os sócios dos clubes em categorias, segundo o seu nível de aperfeiçoamento" (COSTA; SILVA, 2004, p. 23). Se por um lado os fotoclubes promovem a relação entre fotógrafos, troca de experiências e aprendizagem, diversas são as práticas que mantém - e até ampliam - a individualização entre seus integrantes. Se há um movimento de aproximação, principalmente na troca de experiências e fortalecimento político, internamente as barreiras não são quebradas e a fotografia permanece sendo uma atividade individual (Figura 1).

Figura 1 - Fotoclube

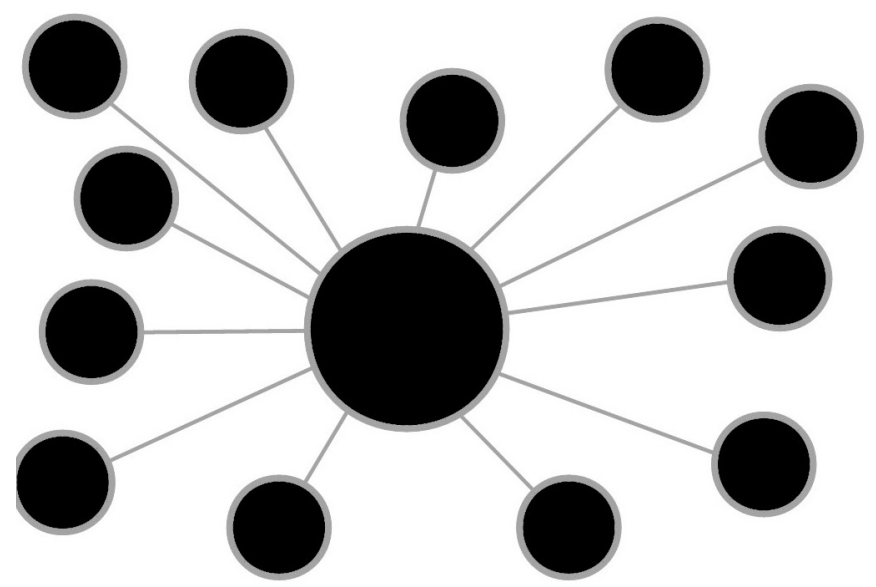

Fonte: do autor. 
Um outro formato agregador de fotógrafos é o da agência fotográfica. A primeira iniciativa deste tipo remonta ao final do século XIX (KOBRÉ, 2011). George Granthan Bain, que era fotógrafo e redator de jornal, inicia, em 1895, a Bain News Photographic Service, em Nova Iorque. Sua ideia era simples e, ao mesmo tempo, inovadora: comprar imagens de correspondentes e jornais de várias partes do país, reproduzi-las e enviar cópias para sua lista de assinantes. Um negócio que expandiu rapidamente, focado na distribuição: comprava, reproduzia e distribuía. O que interessava era a circulação, a comercialização. Não investia na produção e os fotógrafos eram simplesmente fornecedores dentro de uma cadeia produtiva, a ponto de sequer haver uma preocupação com a autoria das mesmas. Rapidamente surgiram várias outras inciativas parecidas e agências de notícias começaram a incorporar o produto foto na sua lista de serviços oferecidos.

Humberto (1983) sugere três tipos de agências, de acordo com seus objetivos e estruturas de trabalho. Uma, muito similar às primeiras experiências como a de George Bain, focada na distribuição, é caracterizada pelas grandes agências internacionais como Agence France Presse (AFP) ou Reuters. Captam imagens com seus fornecedores espalhados pelo mundo e distribuem a seus clientes.

O que move esse modelo é o volume de vendas e a imagem é quase que um commodity ${ }^{1}$. Há uma pulverização tanto de fornecedores quanto de clientes. Como a todo instante existe algum cliente, em algum fuso horário distinto, demandando uma imagem, a velocidade de distribuição, muitas vezes, conta mais que a qualidade. Obviamente que em um mercado tão competitivo, o nível das fotografias é muito alto, mas o que queremos destacar é a importância da agilidade e a valorização do produto imagem: foco nas vendas.

1 Termo importado da economia que designa uma mercadoria - bens ou serviços - para a qual existe uma procura independentemente da distinção de fornecedores (existe um mercado global interessado no produto, sem que haja diferenciação de fornecedor, a exemplo de feijão, açúcar, soja etc). 
Um segundo modelo seria o das agências vinculadas a veículos de comunicação. Neste caso, a ideia de distribuição surge como possibilidade de aumentar a rentabilidade dos veículos através da venda do material excedente, aquele cujo único destino seria o arquivo. Também é focado na distribuição, mas dessa vez em um fluxo de "mão única": as fotos seguem dos veículos produtores para seus clientes, que, por sua vez, não podem ser concorrentes diretos. Ou seja, há o interesse em rentabilizar o material, mas sem que isso entre em choque com questões estratégicas de posicionamento do veículo no seu mercado principal. O volume não é a principal característica pois existem limitações tanto no fornecimento - limitado pela produção do veículo - quanto na circulação - a carteira de clientes não abrange todo o mercado.

Por fim, podemos relacionar as agências independentes, de fotógrafos. São empresas - algumas funcionam como cooperativas - cujo foco se volta para a fotografia e para os fotógrafos. Assumem um formato parecido com os anteriores, buscam a distribuição de seus produtos, mas de modo a valorizar mais o trabalho, de possibilitar um maior aprofundamento nos temas e reconhecimento dos autores. O maior e mais simbólico exemplo é o da francesa Magnum, fundada por Robert Capa, Henri Cartier-Bresson, David Seymor "Chim" e George Rodger, nos idos de 1947. Idealizada por Capa, tinha como principal objetivo formar uma espécie de blindagem entre o fotógrafo e o mercado, garantindo a posse e o controle sobre os negativos, permitindo maior liberdade para o desenvolvimento das coberturas. Até hoje a Magnum inspira o surgimento de novos grupos.

Os vários tipos de agências, com grandes diferenças na sua relação com os fotógrafos, se igualam numa coisa: formam uma estrutura linear ou arborescente, onde os fotógrafos estão ligados às agências que, por sua vez, se ligam ao mercado (Figura 2). 
Figura 2 - Agências fotográficas

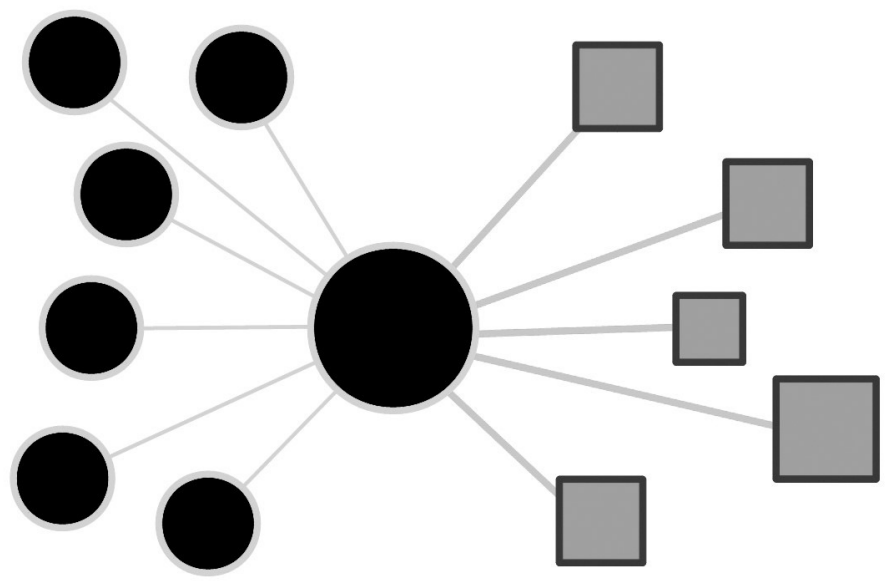

Fonte: do autor

Nos anos 1930, um projeto documental americano também foi responsável por reunir um grande número de fotógrafos: o Farm Security Administration (FSA), um programa do governo Roosevelt, parte de outras ações que visavam a recuperação dos EUA durante o período que ficou conhecido como a Grande Depressão. O FSA foi coordenado por Roy Stryker e empregou fotógrafos como Walker Evans, Dorothea Lange e Gordon Parks, entre muitos outros. Com o intuito de "apresentar a América para os americanos", os fotógrafos viajavam pelo país documentando as famílias, as atividades, as casas, os costumes. Os objetivos do FSA eram, realmente, amplos, pois deveriam atender demandas tanto internas, como órgãos do governo, quanto externas: publicidade, abastecimento de jornais e revistas etc. Roy Stryker providenciava pautas detalhadas sobre o que deveria ser fotografado. Era ele, também, o primeiro a ver os filmes revelados, editando-os, escolhendo as imagens que seguiriam para circulação e as que iriam para o lixo, literalmente. $\mathrm{O}$ acervo hoje depositado na Biblioteca do Congresso americano gira em torno de 160 mil imagens. Estima-se que outro tanto tenha sido 
inutilizado já na primeira edição de Striker. Tagg pontua essa forma de conduzir baseada na encomenda e na edição: "a 'visão geral do mundo' dos arquivos do FSA era, portanto, predominantemente a de Stryker" (TAGG, 2005, p. 218, tradução livre). Apesar de reunir um grupo heterogêneo de fotógrafos em torno de uma produção importante para a fotografia americana e mundial, foi um projeto dirigido por alguém reconhecidamente centralizador. Os fotógrafos não interagiam entre si. Administravam uma relação muitas vezes conflitante entre empregados e empregadores, contratados e contratantes. Cumpriam pautas detalhadas por seu chefe que, por sua vez, era o primeiro a editar o material produzido, definindo os rumos para o trabalho. Puderam imprimir suas visões de mundo e produzir fotografias impressionantes, mas não havia interação entre eles, não compartilhavam o ato fotográfico.

Quando falamos em compartilhar a fotografia em si, queremos dizer permitir uma integração na qual não se possa distinguir, no plano da fotografia, o indivíduo. As experiências sobre as quais nos debruçamos até agora, o fotoclube, a agência ou o FSA, todos eles trabalham a união de fotógrafos, que compartilham diferentes níveis de atividades, mas nunca o fotográfico. Se nos fotoclubes existe uma troca de experiências e aprendizados, nas agências podemos observar que o que une os fotógrafos é a estrutura gerencial ou comercial. No FSA, embora emblemático no conjunto da obra, sempre lembrado como algo que aglutinou importantes nomes da fotografia daquela época, a relação que prevalece entre eles é de "companheiros de trabalho". O que buscamos no nosso debate sobre o coletivo alcançar a fotográfica é observarmos a distinção entre modelos que agem na manutenção da individualidade na fotografia e aqueles que atuam na conformação de um "indivíduo coletivo", um novo indivíduo formado pela junção de vários fotógrafos.

Falamos da Magnum e é impossível falar dela sem citar Robert Capa. Não apenas por ele ter sido um dos fundadores e um dos principais fotógrafos da agência, mas por ser dele boa parte 
das motivações fundamentais da mesma. Estava insatisfeito com o formato adotado pelo mercado da época no qual o fotógrafo não tinha domínio sobre seu trabalho, não desfrutava do reconhecimento e dos desdobramentos: uma vez contratado por um jornal ou revista, era o veículo que decidia como e quando seria usado, incluindo a venda para outros veículos, com respectivo lucro. A ideia de criar uma estrutura que possibilitasse mais valorização do fotógrafo, um maior poder de negociação com o mercado e ganhos na liberdade de trabalho, que podemos simplificar com a escolha dos temas e dos usos de seus trabalhos, através da posse de seus negativos, está tão ligada ao nome Robert Capa quanto à fundação da Magnum.

Algumas questões precedem até mesmo a ascensão de Capa. Nascido na Hungria e fugitivo político, tanto deste país quanto da Alemanha de Hitler, Endre Friedman acaba se estabelecendo na França. A fotografia se coloca como uma possibilidade uma vez que seu desejo era ser jornalista mas o idioma era uma barreira. É da sua companheira, Gerda Taro, a ideia de formarem uma sociedade envolvendo os dois - ele no laboratório e ela na parte comercial com "um rico, famoso e talentoso (além de imaginário) fotógrafo americano chamado Robert Capa", em visita à França (KERSHAW, 2004, p. 28). Uma estratégia de sobrevivência: na verdade os dois fotografavam juntos - aos poucos Friedman iniciava Gerda nesta atividade - em nome do tal fotógrafo famoso, conseguindo se colocar melhor no mercado, impondo preços mais vantajosos e criando um distanciamento entre as transações comerciais e a produção fotográfica. Embora fosse uma farsa, eles negociavam com os clientes em nome de uma outra pessoa, o que tornava a relação mais distante. Vemos aí o embrião da tal "blindagem" a que nos referimos em relação à Magnum. O principal tema fotografado pela dupla - e quase totalmente veiculado com a assinatura de Robert Capa - foi a Guerra Civil Espanhola. Gerda morreu durante esta guerra e, a partir daí, Friedman assumiu completamente a personalidade de Capa, como passa a ser conhecido até o final de sua vida. 
Nesta história e em algumas outras semelhantes, podemos encontrar características do que estamos chamando de compartilhamento no nível da fotografia, um germe da coletivização, uma mescla que nos faz olhar para a experiência não como um agrupamento de indivíduos que continuam isolados, mas como a formação de um novo uno. Independentemente das motivações, Friedman e Taro compartilharam, durante algum tempo, um fazer fotográfico coletivo. Algo que, por motivações distintas, é experienciado de modo ainda mais contundente por um outro casal: Hilla e Bernard Becher, ou, como são mais costumeiramente chamados, simplesmente "os Becher". Eles se conheceram nos anos 1950. Bernard tinha uma formação em pintura, mas havia optado pela fotografia, enquanto Hilla já tinha uma vivência maior com fotografia. Estudaram juntos, resolveram se casar e formaram uma parceria de trabalho que durou perto de 50 anos, até a morte de Bernard em 2007. Suas fotografias de indústrias, minas e outras estruturas são o resultado de uma metodologia de trabalho minuciosa e perfeccionista. Buscavam uma uniformidade na abordagem e na iluminação, independente da localização das obras. Davam preferência a determinadas épocas do ano. Investiam num mapeamento prévio dessas construções - às vezes eles levavam meses entre uma primeira visita de observação até a realização da foto final. Sua pesquisa caminhou para a percepção de padrões e identificação de "tipologias".

No início, compartilhavam o mesmo equipamento, por questões financeiras. Pelo mesmo motivo - não podiam ter um carro nem pagar hotéis -, suas primeiras jornadas foram para locais próximos: Bernard ia na sua moto, carregando o equipamento, Hilla ficava em casa, no laboratório. Essa divisão de trabalho, porém, era apenas superficial: a escolha dos assuntos, a forma como fotografariam, o que se esperava da ampliação, a organização em séries, tudo era fruto de uma constante discussão. Depois as condições melhoraram e puderam passar a viajar juntos, cada um com seu set de equipamento. Mas, ainda assim, continuavam 
combinando as tomadas e os desdobramentos. Muitas vezes, nem eles sabiam quem tinha feito o que num trabalho: "simplesmente isso não é importante", diziam (LANGE, 2006).

A extensa obra dos Becher é um exemplo de quando o coletivo atinge a fotografia. Há um compartilhamento tal que o resultado final, aquela imagem que vai para a parede da exposição ou para a página do livro, é dos dois, independentemente de quem acionou o obturador, de quem esteve presente no local da tomada das imagens. $\mathrm{O}$ que vemos exposto ou publicado não seria possível de outra forma. Esse é um componente crucial para falarmos de um outro modelo que aglutina fotógrafos, que chamaremos de "coletivo fotográfico contemporâneo" e que surge com mais intensidade no início do século XXI.

A nosso ver, algumas características que permeiam a nossa sociedade - e o fazer fotográfico - atualmente potencializam o aparecimento dos coletivos. "A imagem não se reduz à sua visualidade [...]; participam processos que a produzem e pensamentos que a sustentam, [...] cada sociedade necessita uma imagem à sua semelhança" (FONTCUBERTA, 2010, p. 12). Vivemos em um cenário onde a lógica de redes é potencializada pelas novas tecnologias. "Redes constituem a nova morfologia social de nossas sociedades e a difusão da lógica de redes modifica de forma substancial a operação e os resultados dos processos produtivos e de experiência, poder e cultura" (CASTELLS, 2002, p. 565). Tais mudanças atingem tanto a difusão de conteúdos, quanto a comunicação interpessoal e influenciam formas de se relacionar, de pensar e de produzir. Se nos grupos em que se resguarda a condição individual, como nos fotoclubes e agências, podemos perceber uma organização linear ou de "árvore", com um organograma e uma hierarquia previamente definidos, nos coletivos seria mais correto afirmar que predomina a ideia de rede ou, ainda melhor, de "rizoma".

Gilles Deleuze e Félix Guattari (1995), em sua obra "Mil platôs", desenvolvem o conceito de rizoma através de certas 
"características aproximativas". A primeira delas é o princípio de conexão: "qualquer ponto de um rizoma pode ser conectado a qualquer outro e deve sê-lo" (DELEUZE; GUATTARI, 1995, p. 15). No modelo rizomático as conexões não seguem o princípio de causa e efeito, mas as ligações e a forma como elas se modificam a partir do contato é determinado mesmo pela interação entre os pontos. O princípio da heterogeneidade permite que as ligações se façam entre naturezas distintas "põe em jogo regimes de signos muito diferentes" (DELEUZE; GUATTARI, 1995, p. 32). Ao mesmo tempo, um rizoma pode ser quebrado em qualquer ponto e retomado em uma ou outra de suas linhas, mas essas linhas de fuga devem ser vistas, também, como parte do rizoma. Ou seja, "faz-se uma ruptura, traça-se uma linha de fuga, mas corre-se sempre o risco de reencontrar nela organizações que reestratificam o conjunto" (DELEUZE; GUATTARI, 1995, p. 18). Para Kastrup (2010, p. 84), "o rizoma não possui limites definidos, não é uma forma, mas condição de existência das formas. É um tipo de 'estrutura' na qual os elementos encontram-se reunidos numa simultaneidade não unificável".

O cenário contemporâneo é complexo, compreende uma série de pressões e tensões que atingem todas as práticas sociais, nossa maneira de refletir e de se relacionar. Cultura de convergência (JENKINS, 2009), inteligência coletiva (LEVY, 2010) e pósfotografia (RITCHIN, 2010) são apenas alguns dos conceitos que atravessam este cenário e que influenciam nossas práticas. A sociedade muda e a fotografia - ou a forma como nos relacionamos com ela - também se modifica. Se estamos transformando como lidamos com a mídia, a maneira como adquirimos e difundimos conhecimento também é outra. Compartilhar uma informação passa a fazer mais sentido do que guardá-la para si. Muitas vezes, é no processo e na troca que está a importância: a passagem de uma lógica do especialista para a da inteligência coletiva. Um fotógrafo não precisa deter todo o conhecimento necessário para alcançar o resultado final, mas pode compartilhar com outros atores, não 
necessariamente fotógrafos, porções de conhecimento cuja soma permita chegar no mesmo resultado ou, melhor, em algo novo.

Tais associações não são simples para o meio fotográfico, palco de lutas por espaço e reconhecimento do sujeito criador. É preciso lembrar que, por mais que essa luta também tenha se dado em todos os campos, no caso da fotografia, sua condição de massificação aporta outras nuances nesta discussão. Num mundo onde todo mundo fotografa, fincar sua bandeira e impor sua assinatura passa por outras questões. A junção com outros criadores provoca uma diluição da noção de autoria e essa é, muitas vezes, uma outra barreira para a coletivização na fotografia. Um processo, no entanto, que vem sendo naturalizado pelo comportamento cotidiano, pelas práticas corriqueiras. Arlindo Machado aponta como a digitalização ajudou a derrubar alguns tabus da fotografia: "a crença mais ou menos generalizada de que a câmera não mente, de que a fotografia é, antes de qualquer coisa, o resultado imaculado de um registro dos raios de luz refletidos pelo mundo [...] está fadado a desaparecer rapidamente" (MACHADO, 2005, p. 312). Com a massificação da manipulação, naturaliza-se a condição de manipulável.

Figura 3 - Coletivos fotográficos contemporâneos
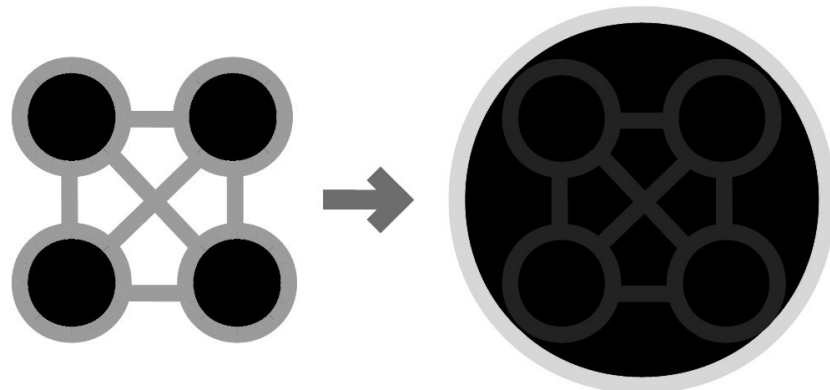

Fonte: do autor 
Da mesma forma, se estamos cada vez mais inseridos em uma prática de apropriações, recriações, releituras e outras intervenções coletivas, como se dá nas redes sociais em volumes inimagináveis, a ideia de uma produção coletiva e o tabu da individualidade também começam a sofrer revisões. As redes não foram inventadas pelas chamadas novas tecnologias, mas as novas tecnologias potencializam as redes como nunca. Os coletivos fotográficos contemporâneos se valem do compartilhamento de conhecimentos na produção de uma obra que é comum a todos os envolvidos. As contribuições entre os integrantes são a característica principal desse modelo. A forma que um coletivo fotográfico toma é fruto das ligações internas, a ponto de operar uma espécie de apagamento das individualidades em prol de um todo coerente (Figura 3). Uma construção rizomática, que estimula a inteligência coletiva, potencializa as trocas, reconfigura as relações de poder e de conhecimento. "Não chegar ao ponto em que não se diz mais EU, mas ao ponto em que já não tem qualquer importância dizer ou não dizer EU" (DELEUZE; GUATTARI, 1995, grifo dos autores). $\mathrm{O}$ coletivo se faz pelas ligações. E tais linhas podem ser rompidas e religadas, sem que seus pontos de conexão sejam de uma mesma natureza.

Um coletivo pode ser formado somente de fotógrafos como pode ter integrantes com outras formações. O coletivo paulista Cia de Foto escolheu a segunda opção. Existiu por dez anos, até 2013, e era composto, em seu núcleo principal, pelos fotógrafos João Kehl, Pio Figueiroa e Rafael Jacinto, além da designer Carol Lopes, que entrou no grupo em 2006. Além deles, haviam vários outros integrantes fixos, em atividades diversas: assistentes, administradores etc. A noção de participação e compartilhamento era tão grande na Cia que eles nunca assinavam individualmente: independentemente de quem estava mais envolvido com o trabalho, o crédito era sempre coletivo. Por trás dessa decisão, havia uma constante participação do grupo nas ideias, nas escolhas estéticas, nas buscas teóricas, na crítica que impulsionava os trabalhos. Uma 
decisão tomada na hora da captação estava fortemente influenciada e conduzida por essa vivência. Creditar o resultado ao grupo acabou sendo algo natural. Apesar de ser um ponto recorrente nos debates sobre coletivos, as questões lançadas pela atuação desses grupos não se restringem a isso. Eles promovem um alargamento dos limites da fotografia.

Tabela 1 - Diferenças entre fotoclube, agência fotográfica e coletivo fotográfico

\begin{tabular}{l|l|l}
\hline Fotoclube & Agência fotográfica & Coletivo fotográfico contemporânc \\
\hline Lógica industrial & Lógica industrial & Lógica pós-industrial \\
Árvore & Árvore & Rizoma \\
Criação individual & Criação individual & Criação em rede \\
Conhecimento compartilhado & Especialista & Conhecimento compartilhado
\end{tabular}

Fonte: do autor

Formar um coletivo fotográfico contemporâneo é mais do que agrupar um certo número de fotógrafos em torno de um objetivo ou de uma estrutura em comum. Em geral esse é o primeiro passo, mas não é suficiente. Os agrupamentos em que as individualidades são mantidas de maneira estanque, sem uma maior porosidade entre os sujeitos criadores, não combinam com o modelo aqui trabalhado (Tabela 1). Também não é garantia de que terão bons resultados fotográficos. O produto da conta pode ser diferente da soma das potencialidades individuais. Não há uma fórmula. $\mathrm{O}$ conjunto se dá no momento mesmo de sua junção. As linhas se constroem pelas ligações que formam. O que o caracteriza está nessas ligações, na forma como elas acontecem e não no resultado como obra. As individualidades são diluídas, há um apagamento em função da criação de um ente formado pelo todo. Mas não um apagamento imposto. Na verdade uma perda do sentido de se falar em individualidades. $\mathrm{O}$ entrosamento naturalmente age nessa mudança. $\mathrm{O}$ coletivo é rizomático. 


\section{Referências}

CASTELLS, Manuel. A sociedade em rede. São Paulo: Editora Paz e Terra, 2002.

COSTA, Helouise; SILVA, Renato Rodrigues da. A fotografia moderna no Brasil. São Paulo: Cosac Naify, 2004.

CRARY, Jonathan. Techniques of the observer. Cambridge: MIT Press, 1990.

DELEUZE, Gilles; GUATTARI, Félix. Mil platôs: capitalismo e esquizofrenia. Tradução de Aurélio Guerra Neto e Celia Pinto Costa. São Paulo: Ed. 34, 1995.

FONTCUBERTA, Joan. La cámara de Pandora: la fotografía después de la fotografía. Barcelona: Gustavo Gili, 2010.

HUMBERTO, Luis. Sobre agências fotográficas. In:

Fotografia: universos e arrabaldes. Rio de Janeiro: Funarte, 1983.

JENKINS, Henry. Cultura da convergência. São Paulo: Aleph, 2009.

KASTRUP, Virgínia. A rede: uma figura empírica da ontologia do presente. In: PARENTE, André (Org.). Tramas da rede: novas dimensões filosóficas, estéticas e políticas da comunicação. Porto Alegre: Sulina, 2010.

KERSHAW, Alex. Blood and champagne: the life and times of Robert Capa. New York: Da Capo, 2004.

KOBRÉ, Kenneth. Fotojornalismo: uma abordagem profissional. Rio de Janeiro: Elsevier, 2011. 
LANGE, Susanne. Bernd and Hilla Becher: life and work. Cambridge: MIT Press, 2006.

LÉVY, Pierre. As tecnologias da inteligência. Tradução de Carlos Irineu da Costa. São Paulo: Ed. 34, 2010.

MACHADO, Arlindo. A fotografia sob o impacto da eletrônica. In SAMAIN, Etiene (Org.). O fotográfico. São Paulo: Editora Hucitec; Editora Senac, 2005.

MCCAULEY, Anne. Escribir la historia de la fotografía antes de Newhall. In: NEWHALL, Beaumont. História de la fotografía. 2. ed. Barcelona: Gustavo Gili, 2002. p. 300-314.

QUEIROGA, Eduardo. Coletivos fotográficos contemporâneos. Curitiba: Appris, 2015.

RITCHIN, Fred. After photography. New York: W. W. Norton, 2010.

SONTAG, Susan. Sobre fotografia. São Paulo: Companhia das Letras, 2004.

TAGG, John. El peso de la representación. Barcelona: Editorial Gustavo Gili, 2005. 